Original Research

\title{
Timing and extension of lymphadenectomy in medullary thyroid carcinoma: A case series from a single institution
}

\author{
Andrea Polistena ${ }^{a,}{ }^{*}$, Alessandro Sanguinetti ${ }^{a}$, Roberta Lucchini ${ }^{\text {a }}$, Sergio Galasse ${ }^{\text {a }}$, \\ Massimo Monacelli a, Stefano Avenia a, Andrea Boccolini a , Louis Banka Johnson b, \\ Nicola Avenia a \\ a University of Perugia, Medical School, Endocrine Surgery Unit, S. Maria University Hospital, Terni, Italy \\ ${ }^{\mathrm{b}}$ University of Lund, Surgical Department, Skåne University Hospital, Malmö, Sweden
}

\section{H I G H L I G H T S}

- Medullary thyroid carcinoma presents with more aggressive behaviour than differentiated tumor.

- Cervical lymphadenectomy has a key role in the treatment of medullary thyroid carcinoma.

- Total thyroidectomy and central dissection is the standard treatment for medullary carcinoma.

- Lateral neck dissection is recommended for US suspicion of lateral neck metastases.

- Central and lateral neck dissection is characterized by potential severe complications.

- Complications can be reduced by correct indications and expertise in specialized centre.

\section{A R T I C L E I N F O}

\section{Article history:}

Received 13 December 2016

Received in revised form

5 April 2017

Accepted 12 April 2017

\section{Keywords:}

Medullary

Thyroid

Carcinoma

Lymph node

Metastases

Surgery

Ultrasound

\begin{abstract}
A B S T R A C T
Background: Medullary thyroid carcinoma is an aggressive tumor and presents with significant morbidity and mortality and a high rate of lymph node metastases. The combination of total thyroidectomy and cervical lymphadenectomy is the essential treatment for those patients presenting with cervical lymph node metastases.

Materials and methods: A retrospective analysis of 117 patients operated for medullary thyroid carcinoma over a period of 15 years at a single institution. Surgical complications and calcitonin levels were noted. Results: Nodal metastases were detected in the central compartment in $72.6 \%$ patients. Positive lymph nodes were detected in the lateral compartment of 34 patients who had undergone ipsilateral dissection and in all 10 patients of those with bilateral surgery. We found 3 cases of unilateral transient recurrent laryngeal nerve palsy, 15 cases of temporary hypoparathyroidism, a permanent accessory nerve lesion and a case of chylous fistula. Normalization of post-operative calcitonin was found in $82.6 \%$ and of patients who underwent total thyroidectomy and central neck dissection alone compared to $35.4 \%$ in those with ipsilateral and bilateral neck dissection.

Conclusions: Total thyroidectomy and cervical lymphadenectomy planned on the ultrasound preoperative study and on the calcitonin level represent the standard of treatment for medullary thyroid carcinoma.
\end{abstract}

@ 2017 IJS Publishing Group Ltd. Published by Elsevier Ltd. All rights reserved.

\footnotetext{
* Corresponding author. UOC Chirurgia Generale e Specialità Chirurgiche, S. Maria University Hospital, University of Perugia, via Tristano di Joannuccio 1, Terni, 05100, Italy. E-mail addresses: apolis74@yahoo.it (A. Polistena), alessandrosanguinetti@gmail.com (A. Sanguinetti), robertalucchini@alice.it (R. Lucchini), galassergio@libero.it (S. Galasse), massimo.monacelli@gmail.com (M. Monacelli), stefano_avenia@libero.it (S. Avenia), a.boccolini86@gmail.com (A. Boccolini), louis.johnson@med.lu.se (L.B. Johnson), nicolaavenia@libero.it (N. Avenia).
} 


\section{Introduction}

Medullary thyroid carcinoma (MTC) presents with significant higher mortality compared to differentiated thyroid carcinoma (DTC) and it is characterized by difficult management due to its aggressive behaviour and to apparently ineffective application of radioiodine ablation (RAI) treatment. MTC in its sporadic presentation accounts for only 5-8\% of all thyroid cancers and in about $20 \%$ of cases it shows an hereditary autosomal dominant transmission [1]. Rare mixed forms of MTC and DTC represent a favourable clinical condition even in metastatic cases where the differentiated compound is present in the lymph nodes the use of post-operative RAI is found to increase therapeutic response $[2,3]$. Surgery is the fundamental therapy for patients affected by MTC including those presenting with cervical lymph node metastases (LNM) [4]. In MTC, LNM are very frequent, being detected in up to $75 \%$ of cases and significantly correlated to tumor size with involved lymph nodes in $20-30 \%$ of tumors less than $1 \mathrm{~cm}$ large, up to $90 \%$ of those larger than $4 \mathrm{~cm}$. The presence of metastases in the central compartment is strictly related to a synchronous involvement of the lateral nodes [5-8]. Level II is involved in up to $20 \%$ of patients presenting as NO in levels III and IV and 20\% of patients with unilateral tumors, even less than $1 \mathrm{~cm}$, both in sporadic and hereditary forms, present contralateral cervical metastastses [5]. This aggressive presentation justifies a more aggressive surgical approach to MTC, compared to what is usually adopted in DTC, where the application of RAI may complement non radical surgery. Extensive lymphadenectomy is often associated with severe complications but these are often balanced by the prognostic advantage on the overall survival after radical primary surgery [9]. High preoperative calcitonin (CT) levels and detection of positive nodes in the central compartment are strictly related to LNM in the laterocervical compartment and even to distant metastases with relevant impact on the overall survival $[10,11]$.

Aim of this study is to assess the results of treatment of medullary carcinoma at our institution in correlation to current available guidelines of treatment provided by the American Thyroid Association (ATA) in 2015 [12].

\section{Materials and methods}

We retrospectively analyzed a case series of 117 resectable MTC consecutively operated by specialists in endocrine surgery, over a period of 15 years (2000-2015) at the Unit of Endocrine Surgery at our institute. This case series is fully compliant with the PROCESS Guidelines [13]. The study was registered in a publicly accessible database (ResearchRegistry.com, registration number: 1942). No ethical approval was required.

Data available in the observational period were collected from our records and analyzed. Preoperative work-out included blood tests, CT-dosage, ECG, chest x-ray, neck ultrasound (US) with preoperative fine needle aspiration cytology (FNAC) and when indicated neck computed tomography and positron emission tomography. The extension of surgical resection was planned preoperatively according to the US detection of suspected lymph nodes and to the preoperative CT levels. In all patients, standard treatment included total thyroidectomy (TT) and central neck dissection (CND) whereas unilateral or bilateral lateral modified radical neck dissection (MRND) were added when involvement of lateral compartment was suspected. Specific indication for ipsilateral MRND synchronous with TT + CND was based on US suspicion of lateral lymph node involvement and on high preoperative CT levels (above $100 \mathrm{pg} / \mathrm{ml}$ ).

Indication to eventually postpone MRND was based on negative US of the lateral compartments before first surgery and postoperatively on positive lymph nodes in the central compartment and on post-operative persistent high levels of CT after $\mathrm{TT}+\mathrm{CND}$. Indication for bilateral MRND was primarily considered for US suspicion of lymph nodes metastases in the lateral compartments and for preoperative CT levels above $200 \mathrm{pg} / \mathrm{ml}$.

The post-operative CT value was analyzed to assess the quality and consistency in the delivery of the intervention. In order to minimize surgical complications, thyroidectomy and lymphadenectomy were carried out as previously reported with preservation of nerves, parathyroids and thoracic duct [14].

The preservation of recurrent laryngeal nerves and of accessory nerves was maintained by direct visualization aided by standard use of intra-operative nerve monitoring (IONM) as previously described $[14,15]$. To evaluate patient outcome, incidence of surgical complications and post-operative CT levels were considered. Follow up was carried out up to at least one year after surgery in the outpatient department.

\subsection{Statistical analysis}

We used Student's $t$-test for analysis of variance between groups when indicated. A $p$-value $<0.05$ was considered statistically significant. All of the data were analyzed using XLSTAT (Addinsoft, New York, NY, USA).

\section{Results}

The present case series included 70 female (59.8\%) and 47 males (40.2\%), with a mean age of $43.7 \pm 9.2$ years. TT plus CND was the standard treatment for all 117 patients. TT and CND were carried out as unique treatment in 69 (59\%) patients with CT level $<30 \mathrm{pg} /$ $\mathrm{ml}$ and with no evidence of lateral nodal involvement. Ipsilateral MRND was added in 38 (32.5\%) patients, where in 15 (39.5\%) and in $23(60.5 \%)$ cases it was respectively syncronous to TT + CND and postponed after histology of the central compartment and detection of post-operative CT. In all 15 patients receiving MRND at first surgery, US was positive in the ipsilateral and negative in the contralateral compartment and CT was above $100 \mathrm{pg} / \mathrm{ml}$. In all 23 patients receiving MRND at a second surgery, US was negative in both lateral compartments but a central compartment involvement after TT + CND and post-operative persistent high levels of CT above $30 \mathrm{pg} / \mathrm{ml}$ were observed. In 10 (8.5\%) other cases bilateral neck dissection was primarily indicated due to positive US of the ipsilateral and contralateral compartments, respectively in $100 \%$ and $80 \%$ of cases and with CT levels above $200 \mathrm{pg} / \mathrm{ml}$ in all patients. In these 10 cases contralateral MRND was postponed at least 30 days after ipsilateral surgery.

In $98 \%$ of cases, patients were discharged in 2nd post-operative day after TT + CND and in the 5th post-operative day following MRND. Nodal metastases were detected in the central compartment in $85(72.6 \%)$ patients. Central metastases were found in 37 (53.6\%) out of 69 patients who had undergone TT + CND and in all 38 who had undergone unilateral and in 10 patients bilateral MRND respectively. Positive lymph nodes were detected in the lateral compartment in all 15 patients undergoing synchronous MRND and in 19 (82.6\%) out of 23 patients undergoing postponed lateral lymphadenectomy. Positive lymph nodes were detected in both lateral compartments in all 10 patients undergoing bilateral MRND. In the 4 cases with negative lateral lymph nodes after ipsilateral postponed MRND, distant metastases were detected after surgery. Data concerning the correlation between surgical procedure, pathology, US evaluation and CT levels are presented in Table 1. In terms of post-operative complications we observed 3 (2.5\%) cases of unilateral temporary laryngeal recurrent nerve palsy and 15 (12.8\%) cases of temporary hypoparathyroidism. Intra-operative 
Table 1

Serum CT and its correlation to histological evidence of metastasis, US preoperative detection and rate of occult metastases in the different treatment groups.

\begin{tabular}{|c|c|c|c|c|c|c|c|c|c|c|}
\hline \multirow[t]{2}{*}{ Treatment } & \multirow[t]{2}{*}{$\mathrm{n}$} & \multicolumn{2}{|c|}{$\begin{array}{l}\text { positive nodes } \\
\mathrm{n}(\%)\end{array}$} & \multicolumn{3}{|c|}{$\mathrm{CT}(\mathrm{pg} / \mathrm{ml})[\mathrm{n}]$} & \multicolumn{2}{|c|}{$\begin{array}{l}\text { US positive nodes } \\
\mathrm{n}(\%)\end{array}$} & \multicolumn{2}{|c|}{$\begin{array}{l}\text { Occult metastases } \\
\mathrm{n}(\%)\end{array}$} \\
\hline & & central & $\begin{array}{l}\text { ipsilateral/ } \\
\text { contralateral }\end{array}$ & $\begin{array}{l}\text { before } \\
\text { surgery }\end{array}$ & $\begin{array}{l}\text { after 1st } \\
\text { surgery }\end{array}$ & $\begin{array}{l}\text { after 2nd } \\
\text { surgery }\end{array}$ & central & $\begin{array}{l}\text { ipsilateral/ } \\
\text { contralateral }\end{array}$ & central & $\begin{array}{l}\text { ipsilateral/ } \\
\text { contralateral }\end{array}$ \\
\hline $\mathrm{TT}+\mathrm{CND}$ alone & 69 & $37(53.6)$ & 1 & $<30[30]$ & $0[30]$ & 1 & $12(32.4)$ & none & $25(67.6)$ & 1 \\
\hline $\begin{array}{l}\text { TT }+ \text { CND + synchronous } \\
\text { ipsilateral MRND }\end{array}$ & 15 & $15(100)$ & $15(100)$ & $>100[15]$ & $0[15]$ & I & $5(33.3)$ & $15 / 0(100)$ & $10(66.7)$ & $0(0)$ \\
\hline $\begin{array}{l}\text { TT }+ \text { CND + differed } \\
\text { ipsilateral MRND }\end{array}$ & 23 & $23(100)$ & $19(82.6)$ & $\begin{array}{l}>30 \\
<100[23]\end{array}$ & $>30[23]$ & $\begin{array}{l}0[19] \\
>30[4]\end{array}$ & $7(30.4)$ & none & $16(69.6)$ & $19(82.6)$ \\
\hline $\begin{array}{l}\text { TT }+ \text { CND + bilateral } \\
\quad \text { MRND }\end{array}$ & 10 & $10(100)$ & $10(100) / 10(100)$ & $>200[10]$ & $>50[10]$ & $\begin{array}{l}<10[7] \\
>50[3]\end{array}$ & $8(80)$ & $8(80) / 6(60)$ & $2(20)$ & $2(20) / 4(40)$. \\
\hline
\end{tabular}

haemorrhage was observed in 1 case of MRND, with bleeding originating from the jugular vein which was directly sutured. Postoperative haemorrhage with bleeding originating from the central compartment was observed in 1 case which required reoperation. A permanent accessory nerve lesion was observed in 1 patient after unilateral MRND. A chylous fistula was observed in 1 patient after left MRND and it was successfully treated conservatively. After a mean follow up of 12 months, basal and stimulated CT presented normal levels in 57 patients (82.6\%) out of 69 undergoing TT + CND and in 17 (35.4\%) out of 48 undergoing ipsilateral and bilateral MRND, with significant difference comparing these two groups of patients $(p<0.05)$. Among 69 cases with TT + CND, all 32 patients with negative lymph nodes presented one year after surgery with normal post-operative CT levels with significant difference $(p<0.05)$ compared to only $25(67.5 \%)$ out of 37 patients with nodal metastases. The remaining 12 patients with positive central compartment undergone TT + CND presented a nodal relapse in the ispilateral compartment (Table 2). Among 31 patients out of 48 who underwent ipsi or bilateral lymphadenectomy and showed high CT levels one year after surgery, nodal relapse was observed in 11 cases and distant metastases in 14 cases (Table 2) whereas 6 patients continued follow up for mild CT increase.

\section{Discussion}

MTC is an extremely aggressive disease compared to DTC and surgery is the unique effective treatment in order to achieve an optimal local control and to improve overall survival [16]. The efficacy of TT and lymph node dissection in DTC and anaplastic carcinoma have been widely investigated [17-19]. Similarly in MTC several studies have suggested that recurrence and survival rates depend upon the adequacy of initial surgery $[9,16]$.

Considering the high rate of nodal involvement, an aggressive approach to cervical metastases is generally supported by many authors [20-24]. The target of lymphadenectomy in MTC is the biochemical efficacy with normal post-operative levels of CT which is observed $90-100 \%$ of patients without metastases and can be even achieved in $30-40 \%$ of patients with lymph node metastases

Table 2

Pattern of nodal relapse and metastases 12 months after surgery.

\begin{tabular}{llll}
\hline Treatment & $\begin{array}{l}\text { Nodal } \\
\text { relapse }\end{array}$ & Site & $\begin{array}{l}\text { Distant } \\
\text { metastases }\end{array}$ \\
\hline $\begin{array}{c}\text { TT + CND alone } \\
\begin{array}{c}\text { TT + CND + synchronous } \\
\text { ipsilateral MRND }\end{array}\end{array}$ & 12 & ipsilateral & None \\
$\begin{array}{c}\text { TT + CND + differed } \\
\text { ipsilateral MRND }\end{array}$ & 4 & contralateral & 2 \\
$\begin{array}{c}\text { TT + CND + bilateral } \\
\text { MRND }\end{array}$ & 2 & contralateral & 4 \\
\hline
\end{tabular}

$[5,25]$. Non detectable postoperative $\mathrm{CT}$ is a fundamental prognostic factor which can be related to better outcome considering that a postoperative normalization predicts a survival rate of $97.7 \%$ at 10 years $[20,21]$. High persistent CT serum levels represent instead a strong marker of residual tumor. Microscopic residual cervical disease, local-regional lymph node infiltration or metastases to distant organs can be suspected in the presence of elevated serum levels of CT even in the absence of clinical or radiographic evidence of disease [21]. The last guidelines for MTC revised by the ATA in 2015 recommend that patients with MTC and no evidence of neck lymph node metastases by US examination and no evidence of distant metastases should have a TT and CND (level VI) [12]. Further, patients with positive pre-operative imaging in the central and lateral neck compartments should be submitted to CND and MRND (levels IIA, III, IV and V) [12]. Preoperative US is therefore a fundamental tool to define the surgical strategy and this was recommended already in the earlier version of ATA guidelines in 2009 [26]. Nevertheless the same guidelines state that very often metastatic lymph nodes are of small size in MTC and do not present specific gross features at surgical exploration as observed for DTC. For this reason the sizes of lymph nodes detected by pre-operative US cannot be considered as an absolute diagnostic criteria [26]. As an alternative parameter to define the surgical strategy, the current guidelines recommend in patients with MTC with no evidence of neck metastases on US and no distant metastases, dissection of lymph nodes in the lateral compartments based on pre-operative serum CT levels [12]. Although the Task Force did not achieve consensus on this recommendation, nevertheless some investigators favour prophylactic MRND in this group of patients. The dilemma of when and what sort of lymphadenectomy to carry out is nowadays based on two different schools of thought, one based on US findings and the other on CT levels. The latter is based on the experience of some authors who argue that elective dissection of US normal ipsilateral central and ispilateral lateral neck compartments is indicated in patients with basal serum CT levels above $20 \mathrm{pg} / \mathrm{ml}$ and similarly the dissection of contralateral lateral neck compartment is indicated for basal CT over $200 \mathrm{pg} / \mathrm{ml}$ [27]. In a large series (Machens et al.) a correlation between the CT levels and the incidence of the involvement of the different cervical levels was observed and specifically it was evident for CT above $20 \mathrm{pg} / \mathrm{ml}$, $50 \mathrm{pg} / \mathrm{ml} 200 \mathrm{pg} / \mathrm{ml}$ and $500 \mathrm{pg} / \mathrm{ml}$ respectively with positivity in the ipsilateral central and ipsilateral lateral compartments, in the contralateral central compartment, in the contralateral lateral compartment and in the upper mediastinum (level VII) [27].

The prognostic advantage of radical surgical clearance has been established but we would like to highlight that these surgical procedures especially MRND are not free from severe surgical complications as we have seen in our institutional series $[9,14]$. Based on above considerations, the choice of the extension of lymphadenectomy and of its timing, is in our opinion a current 
matter of debate since furthermore neither did the ATA task force find a strong level of evidence for the lymphadenectomy guided by the CT levels. In our series we experienced that a safe and effective indication for MRND is supported by the pre-operative US detection which must be as accurate as possible especially in presence of high CT levels, in order not to increase the false negatives. Since we actually observed a high rate of positive nodes in those patients undergoing MRND, one crucial point is to define the correct timing for the lateral lymphadenectomy. MRND synchronous to TT + CND is correctly indicated in cases of suspected positive lymph nodes but when such evidence is not observed, postponing the lateral dissection one month after primary surgery probably does not change the prognosis, if at least the clearance in the central compartment is radical. In our experience this approach assures a clear picture of the nodal status from the pathologist in the central compartment and allows for the detection of the post-operative levels of CT. Furthermore very high CT levels at the time of diagnosis might be associated to distant metastases and this is supported by the evidence of those cases we observed, with negative nodes in the lateral compartment after MRND with still high CT levels. The balance between incidence of surgical complications and the prognostic advantage of a radical approach in MTC is well sustained in those cases with suspected nodal involvement even when a bilateral MRND is indicated. There is evidence that meticulous lymph node dissection has been reported to result in a higher biochemical cure rate [12]. The extension of local-regional lymphadenectomy may improve biochemical cure and survival, although in some cases a more extensive initial surgical resection may increase the rate of complications such as hypoparathyroidism, recurrent laryngeal nerve injury, rarely vagus and accessory nerve damage and thoracic duct injury $[2,26]$. For this reason the option of postponing the MRND after TT + CND in those patients without clear evidence of lateral cervical metastasis, is in our opinion a good option which offers the same rate of radicality while limiting unnecessary dissections and potentially associated complications. This could be a safer alternative compared to the indiscriminate use of CT levels which when very high could be due to distant metastases. In the present series we registered acceptable rates of post-operative complications which once again support the necessity of centralizing MTC patients to referral institutions for endocrine surgery where experience in adequate lymph node assessment can provide valuable prognostic information, reduce recurrence rate and need for further surgery.

This is furthermore suggested by the limited efficacy of chemotherapy and radiotherapy in MTC [26].

\section{Conclusions}

Our findings confirm the role of surgery with adequate lymphadenectomy in MTC patients.

The extension of surgical resection has to be planned according to the preoperative US evaluation of the lymph nodes status in the central and lateral compartments. Nevertheless US in MTC has limits in sensitivity and specificity compared to DTC due to evidence of metastases even in small lymph nodes with gross normal features. Preoperative CT level is a prognostic factor and as can be adopted as a criteria of suspicion for cervical lymph node involvement and must be taken into consideration when planning extension of lymphadenectomy. The present study, in line with ATA recommendations, confirms the necessity of considering multiple factors in the surgical planning for MTC. In our experience the level of preoperative $\mathrm{CT}$ together with the assessment of nodal involvement of the central compartment compensate diagnostic limits of US. Postponed surgery in the lateral compartment is a valid option in order to limit unnecessary complications without affecting an adequate lymph node clearance. Further controlled studies are required to increase the level of evidence of the available guidelines.

\section{Ethical approval}

Not required.

\section{Funding}

This research did not receive any specific grant from funding agencies in the public, commercial, or non profit organisations.

\section{Author contribution}

Andrea Polistena: Participated substantially in conception, design, and execution of the study and in the analysis and interpretation of data; also the drafted and editing of the manuscript.

Alessandro Sanguinetti: Participated substantially in conception, design, and execution of the study and in the analysis and interpretation of data.

Roberta Lucchini: Participated substantially in conception, design, and execution of the study and in the analysis and interpretation of data.

Sergio Galasse: Participated substantially in conception, design, and execution of the study and in the analysis and interpretation of data.

Massimo Monacelli: Participated substantially in conception, design, and execution of the study and in the analysis and interpretation of data.

Stefano Avenia: Participated substantially in conception, design, and execution of the study and in the analysis and interpretation of data.

Andrea Boccolini: Participated substantially in conception, design, and execution of the study and in the analysis and interpretation of data.

Louis Banka Johnson: Participated substantially in conception, design, and execution of the study and in the analysis and interpretation of data.

Nicola Avenia: Participated substantially in conception, design, and execution of the study and in the analysis and interpretation of data; also participated substantially in the drafting and editing of the manuscript.

\section{Conflicts of interest}

None.

\section{Research registration unique identifying number (UIN)}

researchregistry 1942.

\section{Guarantor}

Andrea Polistena MD, corresponding author.

\section{References}

[1] E. Kebebew, P.H. Ituarte, A.E. Siperstein, Q.Y. Duh, O.H. Clark, Medullary thyroid carcinoma: clinical characteristics, treatment, prognostic factors, and a comparison of staging systems, Cancer 88 (2000) 1139-1148.

[2] E. Giove, G. Renzulli, C. Lorusso, D. Merlicco, D. Iacobone, Mixed medullary and follicular carcinoma of the thyroid: report of one case, Ann. Ital. Chir. 75 (2004) 251-256.

[3] M. Costanzo, A. Marziani, V. Papa, M.C. Arcerito, M.A. Cannizzaro, Simultaneous medullary carcinoma and differentiated thyroid cancer. Case report, Ann. Ital. Chir. 81 (2010) 357-360. 
[4] A. Polistena, M. Monacelli, R. Lucchini, R. Triola, C. Conti, S. Avenia, I. Barillaro, A. Sanguinetti, N. Avenia, Approach to lymph node metastases in sporadic medullary thyroid carcinoma. An institutional experience, Ann. Ital. Chir. 86 (2015) 390-395.

[5] F. Pacini, M.G. Castagna, C. Cipri, M. Schlumberger, Medullary thyroid carcinoma, Clin. Oncol. R. Coll. Radiol. 22 (2010) 475-485.

[6] C. Scollo, E. Baudin, J.P. Travagli, B. Caillou, N. Bellon, S. Leboulleux, M. Schlumberger, Rationale for central and bilateral lymph node dissection in sporadic and hereditary medullary thyroid cancer, J. Clin. Endocrinol. Metab. 88 (2003) 2070-2075.

[7] J.F. Moley, M.K. De Benedetti, Patterns of nodal metastases in palpable medullary thyroid carcinoma: recommendations for extent of node dissection, Ann. Surg. 229 (1999) 880-887.

[8] N. Beressi, J.M. Campos, J.P. Beressi, B. Franc, P. Niccoli-Sire, B. Conte-Devolx, A. Murat, P. Caron, L. Baldet, J.L. Kraimps, R. Cohen, J.C. Bigorgne, O. Chabre, P. Lecomte, E. Modigliani, Sporadic medullary microcarcinoma of the thyroid: a retrospective analysis of eighty cases, Thyroid 8 (1998) 1039-1044.

[9] A. Polistena, M. Monacelli, R. Lucchini, R. Triola, C. Conti, S. Avenia, I. Barillaro, A. Sanguinetti, N. Avenia, Surgical morbidity of cervical lymphadenectomy for thyroid cancer: a retrospective cohort study over 25 years, Int. J. Surg. 21 (2015) 128-134.

[10] J.B. Fleming, J.E. Lee, M. Bouvet, P.N. Schultz, S.I. Sherman, R.V. Sellin, K.E. Friend, M.A. Burgess, G.J. Cote, R.F. Gagel, D.B. Evans, Surgical strategy for the treatment of medullary thyroid carcinoma, Ann. Surg. 230 (1999) 697-707.

[11] T.W. Yen, S.E. Shapiro, R.F. Gagel, S.I. Sherman, J.E. Lee, D.B. Evans, Medullary thyroid carcinoma: results of a standardized surgical approach in a contemporary series of 80 consecutive patients, Surgery 134 (2003) 890-899.

[12] S.A. Wells Jr., S.L. Asa, H. Dralle, R. Elisei, D.B. Evans, R.F. Gagel, N. Lee, A. Machens, J.F. Moley, F. Pacini, F. Raue, K. Frank-Raue, B. Robinson, M.S. Rosenthal, M. Santoro, M. Schlumberger, M. Shah, S.G. Waguespack, American thyroid association guidelines task force on medullary thyroid carcinoma. Revised American thyroid association guidelines for the management of medullary thyroid carcinoma, Thyroid 25 (2015) 567-610.

[13] R.A. Agha, A.J. Fowler, S. Rammohan, I. Barai, Orgill DP and the PROCESS group. The PROCESS statement: preferred reporting of case series in surgery, Int. J. Surg. 36 (2016) 319-323.

[14] A. Polistena, P. Di Lorenzo, A. Sanguinetti, C. Buccelli, G. Conzo, A. Conti, M. Niola, N. Avenia, Medicolegal implications of surgical errors and complications in neck surgery: a review based on the Italian current legislation, Open Med. 11 (2016) 298-306.

[15] A. Sanguinetti, A. Polistena, R. Lucchini, M. Monacelli, R. Triola, S. Avenia, I. Barillaro, M.S. Di Patrizi, A. Boccolini, N. Avenia, The role of intraoperative neuromonitoring of recurrent laryngeal nerve and ultrasound scissors use during thyroidectomy: a comparative study on 700 nerves at risk, Minerva Chir. 69 (2014) 29-33.
[16] H. Dralle, I. Damm, G.F. Scheumann, J. Kotzerke, E. Kupsch, H. Geerlings R. Pichlmayr, Compartment-oriented microdissection of regional lymph nodes in medullary thyroid carcinoma, Surg. Today 24 (1994) 112-121.

[17] G. Conzo, A. Polistena, P.G. Calò, P. Bononi, C. Gambardella, C. Mauriello E. Tartaglia, S. Avenia, A. Sanguinetti, F. Medas, G. de Toma, N. Avenia, Efficacy of combined treatment for anaplastic thyroid carcinoma: results of a multinstitutional retrospective analysis, Int. J. Surg. 12 (2014) S178-S182.

[18] G. Conzo, C. Mauriello, G. Docimo, C. Gambardella, G. Thomas, F. Cavallo E. Tartaglia, S. Napolitano, R. Varriale, G. Rossetti, L. Fei, L. Santini, Clinicopathological pattern of lymph node recurrence of papillary thyroid cancer Implications for surgery, Int. J. Surg. 12 (2014) S194-S197.

[19] E. Baldini, C. Tuccilli, N. Prinzi, S. Sorrenti, L. Falvo, C. De Vito, A. Catania, F. Tartaglia, R. Mocini, C. Coccaro, S. Alessandrini, S. Barollo, C. Mian, A. Antonelli, E. De Antoni, M. D'Armiento, S. Ulisse, Deregulated expression of Aurora kinases is not a prognostic biomarker in papillary thyroid cancer patients, PLoS One 10 (2015) e0121514.

[20] E. Modigliani, R. Cohen, J.M. Campos, B. Conte-Devolx, B. Maes, A. Bone M. Schlumberger, J.C. Bigorgne, P. Dumontier, L. Leclerc, B. Corcuff, I. Guilhem, Prognostic factors for biochemical cure in medullary thyroid carcinoma: results in 899 patients, Clin. Endocrinol. 48 (1998) 265-273.

[21] A. Machens, U. Schneyer, H.J. Holzhausen, H. Dralle, Prospects of remission in medullary thyroid carcinoma according to basal calcitonin level, J. Clin. Endocrinol. Metab. 90 (2005) 2029-2034.

[22] R.M. Tuttle, D.W. Ball, D. Byrd, G.H. Daniels, R.A. Dilawari, G.M. Doherty, Q.Y. Duh, H. Ehya, W.B. Farrar, R.I. Haddad, F. Kandeel, R.T. Kloos, P. Kopp, D.M. Lamonica, T.R. Loree, W.M. Lydiatt, J. McCaffrey, J.A. Olson Jr., L. Parks, J.A. Ridge, J.P. Shah, S.I. Sherman, C. Sturgeon, S.G. Waguespack, T.N. Wang, L.J. Wirth, National comprehensive cancer network: medullary carcinoma, J. Natl. Compr. Canc. Netw. 8 (2010) 512-530.

[23] S. Roman, R. Lin, J.A. Sosa, Prognosis of medullary thyroid carcinoma, Am. Cancer Soc. Cancer 107 (2006) 2134-2142.

[24] A.R. Antonelli, C. Piazza, D. Lombardi, F. Casigli, Management of lymph node metastases in well-differentiated and medullary thyroid cancer: retrospective study on 52 cases, Ann. Ital. Chir. 75 (2004) 305-314.

[25] N.H. Esfandiari, D.T. Hughes, H. Yin, M. Banerjee, M.R. Haymart, The effect of extent of surgery and number of lymph node metastases on overall survival in patients with medullary thyroid cancer, J. Clin. Endocrinol. Metab. 99 (2014) $448-454$.

[26] R.T. Kloos, C. Eng, D.B. Evans, G.L. Francis, R.F. Gagel, H. Gharib, J.F. Moley F. Pacini, M.D. Ringel, M. Schlumberger, S.A. Wells Jr., Medullary thyroid cancer: management guidelines of the American thyroid association, Thyroid 19 (2009) 565-612.

[27] A. Machens, H. Dralle, Biomarker-based risk stratification for previously untreated medullary thyroid cancer, J. Clin. Endocrinol. Metab. 95 (2010) 2655-2663. 